\title{
THE EFFECT OF GREEN TEA EXTRACT AS A MATRIX METALLOPROTEINASE INHIBITOR ON THE BOND STRENGTH OF RESIN COMPOSITE
}

\author{
Maha A. El Baz* and Kariem Aboulenien*
}

\begin{abstract}
Objective: the aim of the study was to investigate the effect of epigallocatechin- 3-gallate (EGCG) from green tea extract as collagen cross linking agent on dentin bond durability at different aging times.

Materials and Methods: thirty sound premolars were used, they were divided into two groups (15 each) according to the pretreatment protocol. Mid-coronal flate dentine surface was obtained. Group A had no pretreatment done, where bonding agent was placed as the manufacturer instructions. Group B had EGCG pre-adhesive conditioner rubbed before bonding procedures. Bonding procedure was followed by the application of nano-hybrid resin composite in tygon tubes for micro-shear bond strength measurement. Each group was further subdivided in to three subgroups according the aging protocol, where $\mathrm{T} 1$ specimens were stored for 24 hours, $\mathrm{T} 2$ they were stored for 6 months and T3 they were thermocycled.
\end{abstract}

Results: All data was statistically analyzed, where group B showed statistically significant higher mean bond strength values (19.5 MPa) than group A (12.1MPa) regardless of the aging protocol. There was statistically significant change in micro-shear bond strength results due to aging regardless of the pretreatment. Where T1 revealed the highest mean values (17.1MPa) followed by $\mathrm{T} 3(15.5 \mathrm{MPa})$ and the lowest mean values were reported with group T2. There was a statistically significant decrease in mean micro-shear bond strength from T1 to T2 followed by non-statistically significant change in micro-shear bond strength from $\mathrm{T} 2$ to $\mathrm{T} 3$. The mean micro-shear bond strength at $\mathrm{T} 3$ showed statistically significantly lower value compared to $\mathrm{T} 1$ value.

Conclusion: Green tea extracts (EGCG) is a powerful source of proanthocyanidin that has proved to be a good biological substitute as a cross-linker for preserving the integrity of dentin, enhancing the tooth resin composite inter-face when compared with universal adhesives present now a days in the market.

Recommendation: More long term clinical and laboratory studies are needed to assess the durability of adhesives.

KEYWORDS: Green-tea extract, EGCG, Collagen cross linking agents, MMPs, Micro-shear bond strength.

\footnotetext{
* Lecturer in Conservative Dentistry Department, Faculty of Dentistry, Cairo University.
} 


\section{INTRODUCTION}

Dental resin composites are popular filling materials because of their excellent esthetics, direct-filling capability, and improved load-bearing properties. Contemporary dentin adhesive systems have been considered as the basis of such esthetic restorations. ${ }^{(1)}$

Resin-dentin bonding is considered by many authors as a special form of tissue engineering. This form consists of a matrix of demineralized dentin collagen providing a scaffold for resin infiltration. ${ }^{(2,3)}$

An indestructible, resilient bonding of composite resin with dentin is a considerable long-term challenge in restorative procedures. ${ }^{(4,5)}$ Current clinical studies demonstrated continuous degradation of the dentin-resin bond for different adhesive systems and can also lead to an increase in the failure rates of bonded restorations. ${ }^{(6)}$ Many studies have reported the role of extrinsic factors on contemporary dentin adhesives such as oral fluid and water sorption with subsequent polymer swelling, leading to dentin bond failure. ${ }^{(7,8)} \mathrm{In}$ addition, the activity of host-derived dentin proteases, such as matrix metalloproteinases (MMPs), was found to be responsible for the enzymatic breakdown of improperly impregnated dentin collagen at the resin/ dentin interface. ${ }^{(9,10)}$ Although endogenous matrix proteases are inactive and immobile in mineralized dentin, the application of etch-and-rinse or self-etch adhesives ${ }^{(1)}$ can activate such matrix proteases leading to the degradation of the exposed collagen network from the hybrid layer over time. ${ }^{(12)}$

Two main degradation patterns are seen within the hybrid layer: loss of resin from inter-fibrillar spaces and disorganization of the collagen fibrils suggest the great need of treatment strategies focused not only on the inactivation of dentin proteases but also on improving the biomechanical resistance of collagen structure ${ }^{(13,14)}$.
Different synthetic cross-linking agents (as glutaraldehyde) and natural cross-linkers (grape seed extract, berries etc.) are reported to improve the mechanical properties of dentin collagen matrix $^{(13)}$, resulting in a more stable and durable bond over time. ${ }^{(12)}$ In addition, the application of such cross-linkers was reported to inactivate exposed matrix-bound MMPs. ${ }^{(15)}$

Proanthocyanidin (PA) which is a polyphenolic natural product has been reported to stabilize and increase the cross-linking of dentin, as well as, to decrease the enzymatic degradation, and the swelling ratio of demineralized dentin. ${ }^{(16)}$ Green tea is a great source of Flavonoids which are considered to be a major group of such polyphenolic compounds. Green tea extracts are composed of polyphenols named catechins, such as epicatechin (EC), epigallocatechin (EGC), epicatechingallate(ECG) and epigallocatechin gallate (EGCG). ECG and EGCG were mentioned to be strongly considered as MMP inhibitors. ${ }^{(17)}$ Green tea polyphenols, especially epigallocatechin gallate (EGCG), are able to inhibit the activation of matrix metalloproteinase. ${ }^{(18)}$ In addition, EGCG binds to collagen by hydrogen bonding and hydrophobic interaction, crosslinking collagen and prevent action of collagenase at the treated site. ${ }^{(19,20)}$

This study aimed to investigate the effect of epigallocatechin- 3-gallate (EGCG) from green tea extract as collagen cross linking agent on dentin bond durability at different aging times.

\section{MATERIALS AND METHODS}

The materials used in this study were etch and rinse bonding system from (prime\&bond one- ETCH \& RINSE DENTSPLY, USA), a $36 \%$ phosphoric acid etchant (DeTrey Conditioner DENTSPLY, USA), nanohybrid resin composite (ceram. $\mathrm{x}^{\circledR}$ one UNIVERSAL - DENTSPLY, USA) and natural cross linking agent -green tea extract (EGCG) (Sigma-Aldrich, St. Louis, MO, USA). 
For preparing EGCG-based pre-adhesive conditioner, 0.004 gram of EGCG powder (weighted by a digital analytical balance -AZ 214, Sartorius AG, Germany) was dissolved in $20 \mathrm{ml}$ absolute ethanol. This resulted in an EGCG pre-adhesive conditioner with a final concentration of $0.0002 \mathrm{~g} /$ $\mathrm{ml}$ or $200 \mu \mathrm{g} / \mathrm{ml}$ (EGCG 200) that was used. ${ }^{(21)}$

A total of 30 sound premolars were used, divided into two groups 15 specimens each according to the pretreatment protocol that was done before application of resin composite restorative material (group A and group B). Each group was subdivided into three subgroups according to the aging time after resin composite application.

\section{Specimen preparation:}

All 30 premolars were selected caries and crack free extracted due to orthodontic or periodontal reasons from patients aged 20-40 years. All teeth were cleaned with ultrasonic scalers and polished with a fluoride free polishing paste ( Proxyt medium (RDA 36) Ivoclar Vivadent) to remove all hard and soft tissue deposits. All roots were cut vertically under the cemento-enamel junction with $1 \mathrm{~mm}$. Teeth were then embedded in chemical cured acrylic resin blocks $3 \mathrm{mmX} 3 \mathrm{~mm}$ and then the crown was measured by a digital caliper (CD-6'CS Mitutoyo, Japan) to remove half of it to expose mid coronal dentin. ${ }^{(22)}$ This was done under copious amount of water coolant using a diamond disc (Honeycomb Design 6924, KOMET, USA). Dentin surface was ground flat and perpendicular to the long axis of the tooth using 150 grit silicon-carbide (SIC) paper. Finishing of the specimens was done using 320 grit (SCI) under copious amount of water for 1 minute. To have a standardized smear layer for all tooth specimens a 600 grit (SIC) paper was used for 1 minute with water coolant. ${ }^{21,23(}$ All specimens were then cleaned using an ultrasonic cleaner to remove any tooth debris and stored in distilled water. ${ }^{(24)}$

\section{Treatment of the tooth surface:}

For all specimens dentin was etched using $36 \%$ phosphoric acid etchant for 15 seconds, thoroughly washed with copious amount of water and then lightly dried and excess water was blotted from the surface. ${ }^{(21,25,26,27)}$ For group A, all specimens were treated using etch and bond system without any pretreatments according to the manufacturer instructions, where the bonding agent was applied and agitated with the aid of micro-brush in two successive layers for 15 seconds, then it was gently blown with air to ensure excess solvent removal. ${ }^{(21,28)}$ For group B, pretreatment of dentin was done using EGCG-based pre-adhesive conditioner, were all dentin surface was rubbed by the aid of micro-brush for 60 seconds with the conditioner. Then the bonding agent was applied according to the manufacturer instruction as done with group $\mathrm{A}^{(21)}$.

For both groups $\mathrm{A}$ and $\mathrm{B}$ after bonding agent application two tygon tubes (inside diameter of $0.8 \mathrm{~mm}$ and height of $0.8 \mathrm{~mm}$ ) (TYG-030, Small Parts Inc, Miami Lakes, FL, USA) ${ }^{(43)}$ were placed on the treated surface then the bonding agent was light cured for 20 seconds using Elipar ${ }^{\mathrm{TM}}$ S10 LED curing light (3M ESPE, Germany) . Resin composite was then injected inside the tube carefully to ensure no air bubble entrapped and light cured for 40 seconds. Tygon tubes were left not removed for micro-shear testing by the universal testing machine (Lloyd LR 5k, Lloyd Instruments Ltd., Hampshire, UK). Specimens were then stored in distilled water accordingly to the aging protocol.

Each group was further subdivided into three subgroups (5 specimens each) according to the time of storage where for $\mathrm{T} 1$ specimens were stored in distilled water for 24 hours at $37^{\circ} \mathrm{C}$, for $\mathrm{T} 2$ specimens were stored in distilled water for 6 months at $37^{\circ} \mathrm{C}$ and for T3 specimens were thermo-cycled using Mechatronic thermo-cycler (THE-1100, Germany) , for 5000 cycles between $5^{\circ} \mathrm{C}$ and $55^{\circ} \mathrm{C}$, with the 
time in each bath was 15 seconds and a transfer time of 5 seconds. ${ }^{(29,30)}$

Micro-shear testing procedure was done using thin wire steel $(0.18 \mathrm{~mm})$ that was looped around the resin composite tubes, the wire loop was kept parallel to the load cell movement direction and the bonded surface. ${ }^{(31)}$ Tensile force of a crosshead speed of $1 \mathrm{~mm} / \mathrm{min}$ was applied to the specimens at the tooth restoration interface till de-bonding occurred. Bond strength results were obtained using software (Nexygen software) by dividing the debonding forces on the surface area. All data were then statistically analyzed.

\section{Statistical Analysis}

Numerical data were explored for normality by checking the distribution of data and using tests of normality (Kolmogorov-Smirnov and ShapiroWilk tests). Data showed normal (parametric) distribution. Data were presented as mean, standard deviation (SD) and 95\% Confidence Interval (95\% $\mathrm{CI})$ for the mean values.

Two-way Analysis of Variance (ANOVA) was used to study the effect of pretreatment, aging and their interaction on mean micro-shear bond strength. Bonferroni's post-hoc test was used for pair-wise comparisons when ANOVA test is significant.

The significance level was set at $\mathrm{P} \leq 0.05$.
Statistical analysis was performed with IBM $^{\circledR}$ SPSS ${ }^{\circledR}$ Statistics Version 20 for Windows.

\section{RESULTS}

\section{Two-way ANOVA results}

The results showed that pretreatment had a statistically significant effect on mean micro-shear bond strength $(P$-value $<0.001$, Effect size $=0.999)$. Aging had also a statistically significant effect on mean micro-shear bond strength $(P$-value $<0.001$, Effect size $=0.713)$. The interaction between the two variables had a statistically significant effect on mean micro-shear bond strength $(P$-value $<0.001$, Effect size $=0.928)$. Since the interaction between the variables is statistically significant, so the variables are dependent upon each other. (Table 1)

The observed power for the pretreatment and aging variables was 1.000 and 1.000 respectively, indicating an adequate sample size.

\section{Effect of pretreatment regardless of aging}

Regardless of aging, no pretreatment (group A) gave a mean of micro-shear bond strength of 12.1 MPa showed statistically significantly lower value than pretreatment with EGCG (group B) giving a mean of micro-shear bond strength of $19.5 \mathrm{MPa}$ $(P$-value $<0.001$, Effect size $=0.999)$. (Table 2 and Figure 1)

TABLE (1): Two-way repeated measures ANOVA results for the effect of pretreatment and aging on mean micro-shear bond strength

\begin{tabular}{|l|l|l|l|l|l|c|c|}
\hline Source of variation & $\begin{array}{l}\text { Type III Sum } \\
\text { of Squares }\end{array}$ & df & $\begin{array}{l}\text { Mean } \\
\text { Square }\end{array}$ & F-value & P-value & $\begin{array}{c}\text { Partial Eta } \\
\text { Squared } \\
\text { (Effect size })\end{array}$ & $\begin{array}{c}\text { Observed } \\
\text { power }\end{array}$ \\
\hline Pretreatment & 407.0 & 1 & 407.0 & 927.8 & $<0.001 *$ & 0.999 & 1.000 \\
\hline Aging & 26.1 & 2 & 13.0 & 29.8 & $<0.001 *$ & 0.713 & 1.000 \\
\hline Pretreatment x Aging interaction & 136.2 & 2 & 68.1 & 155.2 & $<0.001 *$ & 0.928 & 1.000 \\
\hline
\end{tabular}

df: degrees of freedom $=(n-1)$, *: Significant at $P \leq 0.05$ 
TABLE (2): The mean, standard deviation (SD), 95\% Confidence Interval (95\% CI) values and results of two-way ANOVA test for comparison between micro-shear bond strength without and with pretreatment regardless of aging

\begin{tabular}{|c|c|c|c|c|}
\hline \multicolumn{2}{|c|}{ No pretreatment } & \multicolumn{2}{c|}{ EGCG } & \multirow{2}{*}{ P-value } \\
\cline { 1 - 3 } Mean & $95 \% \mathrm{CI}$ & $\begin{array}{c}\text { Mean } \\
\text { (SD) }\end{array}$ & $95 \% \mathrm{CI}$ & \\
\hline \multirow{2}{*}{$12.1(2.9)$} & $11.8-$ & $19.5(2.0)$ & $\begin{array}{c}19.2- \\
19.9\end{array}$ & $<0.001 \%$ \\
\hline
\end{tabular}

*: Significant at $P \leq 0.05$

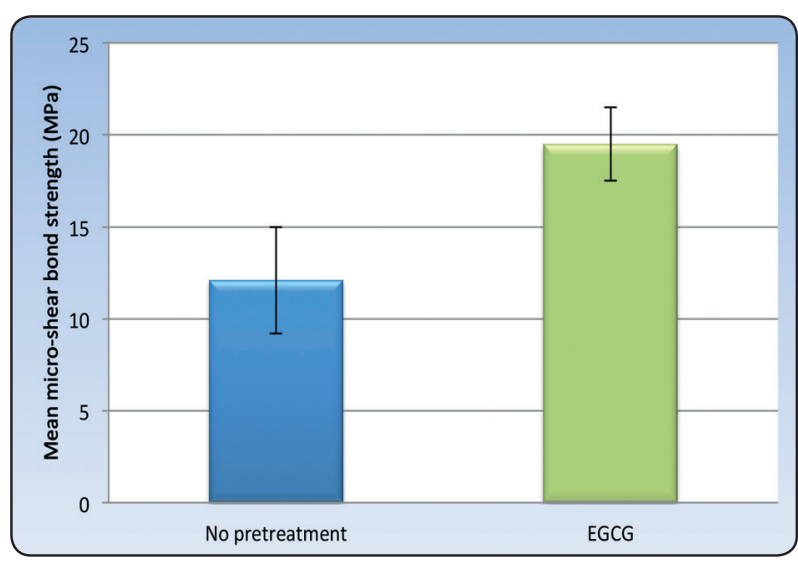

Fig. (1) Bar chart representing mean and standard deviation values for micro-shear bond strength without and with pretreatment regardless of aging

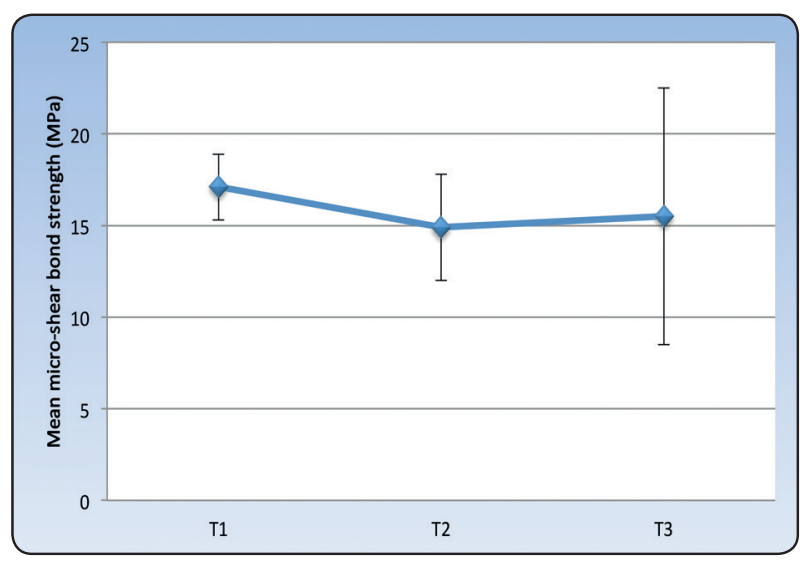

Fig. (2): Line chart representing mean and standard deviation values for micro-shear bond strength at aging periods regardless of pretreatment from $\mathrm{T} 2$ to T3. The mean micro-shear bond strength at $\mathrm{T} 3$ showed statistically significantly lower value compared to T1 value. (Table 3 and Figure 2)

TABLE (3): The mean, standard deviation (SD), 95\% Confidence Interval (95\% CI) values and results of two-way ANOVA test for comparison between micro-shear bond strength at different aging periods regardless of pretreatment

\begin{tabular}{|c|c|c|c|c|c|c|}
\hline \multicolumn{2}{|c|}{ T1 } & \multicolumn{2}{c|}{ T2 } & \multicolumn{2}{c|}{ T3 $P$-value } \\
\cline { 1 - 5 } Mean (SD) & $95 \%$ CI & Mean (SD) & $95 \%$ CI & Mean (SD) & $95 \%$ CI & \\
\hline $17.1(1.8)^{\mathrm{A}}$ & $16.7-17.5$ & $14.9(2.9)^{\mathrm{B}}$ & $14.5-15.3$ & $15.5(7.0)^{\mathrm{B}}$ & $15.0-15.9$ & $<0.001 *$ \\
\hline
\end{tabular}

\footnotetext{
*: Significant at $P \leq 0.05$, Different superscripts are statistically significantly different
} 


\section{Effect of different interactions}

\section{a) Comparison between no pretreatment and pre- treatment with EGCG:}

At T1; no pretreatment showed statistically significantly lower mean micro-shear bond strength than EGCG $(P$-value $<0.001$, Effect size $=0.728)$, where group A revealed $15.4 \mathrm{MPa}$ as a mean of micro-shear bond strength and group $\mathrm{B}$ revealed $18.8 \mathrm{MPa}$.

At T2; no pretreatment showed statistically significantly lower mean micro-shear bond strength than EGCG ( $P$-value $<0.001$, Effect size $=0.877)$, where group A revealed $12.2 \mathrm{MPa}$ as a mean of micro-shear bond strength and group B revealed 17.6 MPa.

At T3; no pretreatment showed statistically significantly lower mean micro-shear bond strength than EGCG $(P$-value $<0.001$, Effect size $=0.977)$, where group A revealed $8.8 \mathrm{MPa}$ as a mean of micro-shear bond strength and group $\mathrm{B}$ revealed 22.1 MPa. (Table 4 and Figure 3)

\section{b) Comparison between aging periods}

With no pretreatment; there was a statistically significant change in mean micro-shear bond strength by aging $(P$-value $<0.001$, Effect size $=$ 0.911). Pair-wise comparisons between the aging periods revealed that there was a statistically significant decrease in mean micro-shear bond strength from T1 to T2 as well as from T2 to T3. The mean micro-shear bond strength level at $\mathrm{T} 3$ showed statistically significantly lower value compared to $\mathrm{T} 1$ value.

With EGCG pretreatment; there was a statistically significant change in mean micro-shear bond strength by aging ( $P$-value $<0.001$, Effect size $=0.837)$. Pair-wise comparisons between the aging periods revealed that there was a statistically significant decrease in mean micro-shear bond strength from T1 to T2 followed by a statistically significant increase in micro-shear bond strength from T2 to T3. The mean micro-shear bond strength at $\mathrm{T} 3$ showed statistically significantly higher value compared to T1 value. (Table 4 and Figure 3)

TABLE (4): The mean, standard deviation (SD), 95\% Confidence Interval (95\% CI) values and results of twoway ANOVA test for comparison between micro-shear bond strength of the different interactions

\begin{tabular}{|c|c|c|c|c|c|c|}
\hline \multirow[b]{2}{*}{ Time } & \multicolumn{2}{|c|}{ No pretreatment } & \multicolumn{2}{|c|}{ EGCG } & \multirow{2}{*}{$\begin{array}{l}\text { Partial Eta } \\
\text { Squared } \\
\text { (Effect size) }\end{array}$} & \multirow{2}{*}{$\begin{array}{c}\text { P-value } \\
\text { (Between no } \\
\text { pretreatment } \\
\text { and EGCG) }\end{array}$} \\
\hline & Mean (SD) & $95 \% \mathrm{CI}$ & Mean (SD) & $95 \% \mathrm{CI}$ & & \\
\hline $\mathrm{T} 1$ & $15.4(0.7)^{\mathrm{A}}$ & $14.8-16.0$ & $18.8(0.2)^{\text {в }}$ & $18.2-19.4$ & 0.728 & $<0.001 *$ \\
\hline $\mathrm{T} 2$ & $12.2(0.9)^{\mathrm{B}}$ & $11.6-12.8$ & $17.6(0.3)^{\mathrm{C}}$ & $17.0-18.2$ & 0.877 & $<0.001 *$ \\
\hline $\mathrm{T} 3$ & $8.8(0.8)^{\mathrm{C}}$ & $8.2-9.5$ & $22.1(0.7)^{\mathrm{A}}$ & $21.5-22.7$ & 0.977 & $<0.001 *$ \\
\hline $\begin{array}{l}\text { Partial Eta Squared } \\
\text { (Effect size) }\end{array}$ & \multicolumn{2}{|c|}{0.911} & \multicolumn{2}{|c|}{0.837} & & \\
\hline $\begin{array}{l}P \text {-value } \\
\text { (Between aging periods) }\end{array}$ & \multicolumn{2}{|c|}{$<0.001 *$} & \multicolumn{2}{|c|}{$<0.001 *$} & & \\
\hline
\end{tabular}

*: Significant at $P \leq 0.05$, Different superscripts in the same column are statistically significantly different 


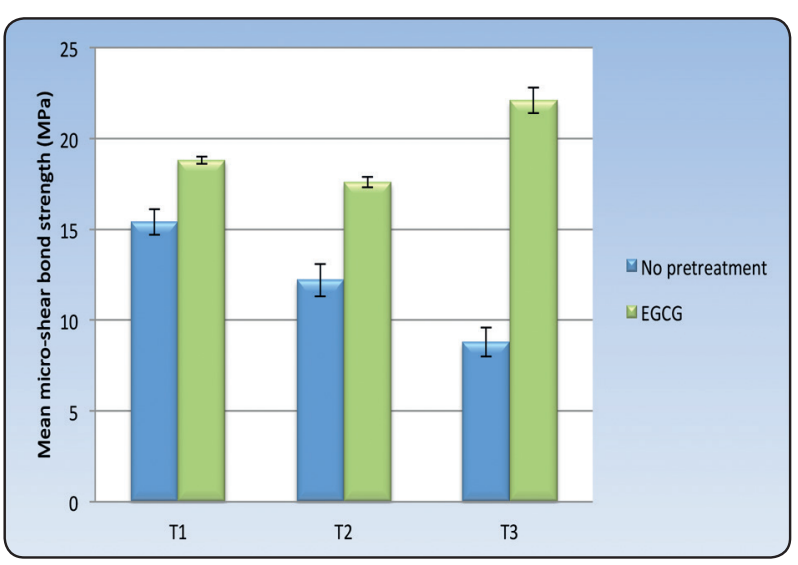

Fig. (3): Bar chart representing mean and standard deviation values for micro-shear bond strength of the different interactions.

\section{DISCUSSION}

In our current study we have compared the efficiency of the green tea extract (EGCG) as collagen cross-linkers with the total-etch adhesive system present in the market at different storage time intervals. The results were in agreement with the research hypothesis. Fonseca et al in $2013^{(32)}$ compared several MMPs inhibitors and crosslinking agents on bond strength, EGCG showed the best results in comparison to chlorohexidine, hyaluronic acid and vitamin C. Demeule et al in $2000^{(33)}$ and John $\mathrm{K}$ et al in $2010^{(34)}$ reported the inhibitory effect of EGCG on MMP activity and collagen degradation.

The EGCG was applied on etched dentin for 60 seconds which is considered a clinically relevant time period before applying the bonding agent. The use of it as a pre-adhesive conditioner was suggested by M. Fang et al in $2012^{(35)}$ and H. Yang et al in 2016. ${ }^{(21)}$ In the present study, the pretreated dentin specimens with the EGCG group B showed a mean of $19.5 \mathrm{MPa}$ followed by the no-pretreated dentin specimens group A $12.1 \mathrm{Mpa}$ with a statistically significant difference between these two groups. (Table 2 and Figure 1)
Different bond strength tests have been advocated to evaluate dental adhesives. The most commonly used are the shear and tensile tests. Moreover, micro-bond tests are used to evaluate adhesives at small areas. ${ }^{(36)}$ Storage of specimens in water has been used invitro to age adhesives, in addition to aging thermo-cycling is commonly used to simulate thermal changes that occur in the oral environment. ${ }^{(37)}$ Most of the invitro bond strength tests are performed after 24 hours of water storage of the specimens. In the oral environment the interface is subjected to different kinds of stresses immediately after placement. ${ }^{(36)}$ Thermocycling was done in an attempt to assess the ability of EGCG to maintain collagen stabilization under fluctuating temperatures. This protocol was done according to the ISO. ${ }^{(30)}$ the 5000 cycles of thermocycling was proven to be equivalent to 6 months storage in water. This was the same protocol that was followed by De Munck et al in $2005^{(38)}$ based on the hypothesis that around 20-30 cycles of temperature fluctuation might occur daily intra-orally.

After studying the aging on all the specimens treated, the highest was recorded 17.1 $\mathrm{MPa}$ for aging time if $\mathrm{T} 1$ (24hours group) followed by T3 (thermocycled group) $15.5 \mathrm{MPa}$ and the lowest mean microshear bond strength was for $\mathrm{T} 2$ which showed 14.9 MPa (6 months aging). (Table 3 and Figure 2) This was in agreement with finding of Castellen et al in $2013^{(23)}$ and Vidal et al in 2014. ${ }^{(39)}$ However, our results were not in agreement with De Munck et al in 2012 as they found out that there was no correlation between aging time and bond strength. ${ }^{(40)}$

Adhesives have a main function of providing retention to resin composite fillings and adhesives. It should withstand all mechanical forces in addition to be able to prevent leakage along the interface. The prime bonding mechanism is its bond to enamel and dentin. The inorganic part of the tooth structure is replaced by resin monomers that are achieved 
mainly by diffusion and capillarity to obtain micromechanical retention. ${ }^{(41)}$ The exposure of collagen matrix of dentin by acid etching may activate MMPS which is evident to cause collagenolysis in presence of water due to nano-leakage. ${ }^{(42)}$ This lead to the increase of awareness of adding MMPs inhibitors to the adhesives, or even adding molecules that block its expression by odontoblasts. The release and activation of MMPs could be due to the decreased pH of the adhesives products. ${ }^{(43)}$ Endogenous MMPs are proteolytic enzymes that are involved in dentin collagen breakdown and the biodegradation of its organic matrix. These enzymes are activated during caries process and progression. ${ }^{(44)}$ The release and activation of MMPs during bonding procedure are thought to be responsible for in vitro thinning and disappearance of collagen fibrils from the hybrid layer that is incompletely infiltrated. ${ }^{(45)}$

The most popular beverage consumed by humans worldwide is TEA. So having an alternative cariostatic agent than fluorides was a must. Tea leaves was proven to possess antioxidant, antimutagenic, antidiabetic, hypocholesterolemic, antibacterial, anti-inflammatory, and cancer preventive properties. (46) The bio-adhesion mechanism involves physicochemical modifications to the dentin matrix, reduced tissue biodegradation, and bridging to methacrylate resins. ${ }^{(47)}$

According the results of this study the most surprising result of this research is that the green tea extract increased the etch-and-rinse adhesive system bond strength. Bond stability has been reported using green tea extract in 6 months of water storage. ${ }^{(48)}$ All groups have shown decrease in microshear bond strength values However, after 6 months of storage in water, the bond remained stable, with showing beneficial effects. ${ }^{(49)}$ In fact, it has been proposed that the application of a solution containing the main catechin in green tea - epigallocatechin gallate (EGCG) - in pretreatment form ${ }^{(50)}$ promotes significant bonding stability to dentin, compared with the no pre-treatment group.
Moreover, because the studies evaluating green tea extract and EGCG solutions on dentin are scarce, and because most studies have been conducted on sound dentin, the comparison of results has been rendered difficult. It is speculated that green tea extract could have increased the bond strength of the etch-and-rinse adhesive system because it was tested on caries-affected dentin, where the occurrence of MMPs and cysteine cathepsins is aggravated. (28) Additionally, because green tea polyphenol contains EGCG, it has been classified as a proanthocyanidin (PAC), a highly hydroxylated structure capable of forming an insoluble complex with proteins. (51) For this reason, green tea polyphenol has been advocated as a natural collagen cross-linking agent, able to enhance the mechanical properties of dentin and to reduce the dentin biodegradability of hostderived MMPs. ${ }^{(51)}$

The use of these natural derivatives are affected by many factors such as solvents used for preparation, the source of these natural products, the extracted process of the products, $\mathrm{pH}$, time of application and temperature may also affect the structure of PA and its overall cross- linking potential. ${ }^{(52,53)}$ Therefore, it is important to analyze the effect of the PA-based pre-conditioners dissolved in different polar solvents on the properties of dentin matrix, and further optimize the conditions for potential clinical applications, having a direct effect on the tensile bond strength values. In the present study, ethanol was used as suggested by Pashley et al in 2002(26) and Sadek et al in $2008{ }^{(54)}$ in attempts to engage the benefit of EGCG with ethanol bonding philosophy.

\section{CONCLUSION}

Green tea extracts (EGCG) is a powerful source of proanthocyanidin that has proved to be a good biological substitute as a cross-linker for preserving the integrity of dentin, enhancing the tooth resin composite inter-face when compared with universal adhesives present now a days in the market. 


\section{RECOMMENDATION}

Further studies are recommended for these natural substitutes to be used during our daily practice, or to be directly incorporated with present restorative materials.

More long term clinical and laboratory studies are needed to assess the durability of adhesives.

\section{REFERENCES}

1. Delaviz Y, Finer Y, Santerre P. Biodegradation of resin composites and adhesives by oral bacteria and saliva: A rationale for new material designs that consider the clinical environment and treatment challenges. Dent Mate... 2014; 30:16-20.

2. Liu Y, Tjäderhane L, Breschi L, Mazzoni A, Li N, Mao J, Pashley DH, Tay FR. Limitations in bonding to dentin and experimental strategies to prevent bond degradation. J Dent Res. 2011; 90: 953-68.

3. Carvalho RM, Manso AP, Geraldeli S, Tay FR, Pashley DH. Durability of bonds and clinical success of adhesive restorations. Dent Mater 2012; 28:72-86.

4. Macedo GV, Yamauchi M, Bedran-Russo AK. Effects of chemical cross-linkers on caries-affected dentin bonding. J Dent Res 2009; 88:1096-100.

5. Sattabanasuk V, Shimada Y, Tagami J. Effects of saliva contamination on dentin bond strength using all-in-one adhesives. J Adhes Dent 2006; 8:311-8.

6. Hiraishi N, Kitasako Y, Nikaido T, Nomura S, Burrow MF, Tagami J. Effect of artificial saliva contamination on $\mathrm{pH}$ value change and dentin bond strength. Dent Mater 2003; 19:429-34.

7. Gupta N, Tripathi AM, Saha S, Dhinsa K, Garg A. Effect of saliva on the tensile bond strength of different generation adhesive systems: An in-vitro study. J Clin Diagn Res 2015.

8. Mazzoni A, Pashley DH, Nishitani Y, Breschi L, Mannello F,Tjäderhane L, et al. Reactivation of inactivated endogenous proteolytic activities in phosphoric acidetched dentine by etch-and-rinse adhesives. Biomaterials 2006; 27(25):4470-6.

9. Nascimento FD, Minciotti CL, Geraldeli S, Carrilho MR,Pashley DH, Tay FR. Cysteine cathepsins in human carious dentin. J Dent Res 2011; 90(4):506-11.
10. Tay FR, Pashley DH, Loushine RJ, Weller RN, Monticelli F,Osorio R. Self-etching adhesives increase collagenolytic activity in radicular dentin. J Endod 2006;32(9):862-8.

11. Tjäderhane L, Nascimento FD, Breschi L, Mazzoni A,Tersariol IL, Geraldeli S, et al. Strategies to prevent hydrolytic degradation of the hybrid layer-a review. Dent Mater 2013; 29(10):999-1011.

12. Tezvergil-Mutluay A, Agee KA, Uchiyama T, Imazato S,Mutluay MM, Cadenaro M. The inhibitory effects of quaternary ammonium methacrylates on soluble and matrix-bound MMPs. J Dent Res 2011; 90(4):535-40.

13. Al-Ammar A, Drummond JL, Bedran-Russo AK. The use of collagen cross-linking agents to enhance dentin bond strength. J Biomed Mater Res B Appl Biomater2009; 91(1):419-24.

14. Seseogullari-Dirihan R, Mutluay MM, Vallittu P, Pashley DH,Tezvergil-Mutluay A. Effect of pretreatment with collagen crosslinkers on dentin protease activity. Dent Mater2015;31(8):941

15. Seseogullari-Dirihan R, Apollonio F, Mazzoni A, TjaderhaneL, Pashley D, Breschi L. Use of crosslinkers to inhibit dentin MMPs. Dent Mater 2016;32:423-32.

16. Castellan CS, Pereira PN, Grande RH, Bedran-Russo A. Mechanical characterization of proantocyanidin-dentin matrix interaction. Dental Materials. 2010; 26(10).

17. Zhang SC, Kern M. The Role of Host-derived Dentinal Matrix Metalloproteinase in Reducing Dentin Bonding of Resin Adhesives. Int J Oral Sci.2009; 1: 163-76.

18. Hwang JY, Choi SC, Park JH, Kang SW. The use of green tea extract as a storage medium for the avulsed tooth. J Endod 2011; 37: 962-967.

19. Chen H, Huang B. Epigallocatechin-3-gallate: a novel storage medium for avulsed teeth. Dent Traumatol 2012; 28:158-160.

20. Jung IH, Yun JH, Cho AR, Kim CS, Chung WG, Choi SH. Effect of epigallocatechin-3-gallate on maintaining the periodontal ligament cell viability of avulsed teeth: a preliminary study. J Periodontal Implant Sci 2011; 41: 10-16.

21. Yang H, Guo J, Deng D, Chen Z, Huang C. Effect of adjunctive application of epigallocatechin-3-gallate and ethanol-wet bonding on adhesive-dentin bonds. J Dent.2016; 44:44-9. 
22. Perdigao J, Swift Jr EJ, Denehy GE, Wefel JS, Donly KJ. In vitro Bond Strengths and SEM Evaluation of Dentin Bonding Systems to Different Dentin Substrates. J Dent Res. 1994; 73: 44-55.

23. Castellan CS, Bedran-Russo AK, Antunes A, Pereira PN. The effect of dentin biomodification using natural crosslinkers: One-Year Bond Strength Study. Int J Dent.2013; 918010 .

24. Secilmis A, Dilber E, Gokmen F, Ozturk N, Telatar T. Effects of storage solutions on mineral contents of dentin. J Dent Sci. 2011;6: 189-94

25. Pashley DH, Tay FR, Breschi L, Tjäderhane L, Carvalho RM, Carrilho M, Tezvergil-Mutluay A. State of the art etch-and-rinse adhesives. Dent Mater. 2011; 27: 1-6.

26. Pashley DH, Carvalho RM, Tay FR, Agee KA, Lee KW. Solvation of dried dentin matrix by water and other polar solvents. Am J Dent. 2002; 15:97-102.

27. Tezvergil-Mutluay A, Mutluay M, Seseogullari-Dirihan R, Agee KA, Key WO, Scheffel DL, Breschi L, Mazzoni A, Tjäderhane L, Nishitani Y, Tay FR. Effect of phosphoric acid on the degradation of human dentin matrix. J Dent Res.2013;92:87-91

28. Du $\mathrm{X}$, Huang $\mathrm{X}$, Huang $\mathrm{C}$, Wang $\mathrm{Y}$, Zhang $\mathrm{Y}$. Epigallocatechin-3-gallate (EGCG) enhances the therapeutic activity of a dental adhesive. J Dent. 2012 ;40:485-92

29. Baracco B, Fuentes MV, Garrido MA, González-López $\mathrm{S}$, Ceballos L.Effect of thermal aging on the tensile bond strength at reduced areas of seven current adhesives. Odontology. 2013; 101:177-85.

30. International Standards Organization (ISO). Dentistry Testing of adhesion to tooth structure. ISO/TS 11405:2015

31. Armstrong S, Geraldeli S, Maia R, Raposo LH, Soares CJ Yamagawa J. Adhesion to tooth structure: A critical review of "micro" bond strength test methods. Dent Mater.2010; 26:50-62.

32. Da Fonseca BM, Pleffken PR, Balducci I, Tay F, Pucci CR, Araujo MA. New trends in dentin bonding: treatment with Chlorhexidine, Hyaluronic acid, vitamin $\mathrm{C}$ and green tea. Braz Dent Sci.2013; 16:56-62.

33. Demeule M, Brossard M, Pagé M, Gingras D, Béliveau R. Matrix metalloproteinase inhibition by green tea catechins. Biochim. Biophys. Acta.2000; 1478: 51-60.
34. Jackson JK, Zhao J, Wong W, Burt HM. The inhibition of collagenase induced degradation of collagen by the galloylcontaining polyphenols tannic acid, epigallocatechin gallate and epicatechin gallate. J Mater Sci. 2010; $21: 1435-43$

35. Fang M, Liu R, Xiao Y, Li F, Wang D, Hou R, Chen J. Biomodification to dentin by a natural crosslinker improved the resin-dentin bonds. J Dent. 2012 Jun 30; 40:458-66.

36. Choltacha Harnirattisai, Panitta Roengrungreang, Utumporn Rangsisiripaiboon And Pisol Senawongse. Shear and micro-shear bond strengths of four self-etching adhesives measured immediately and 24 hours after application. Dental Materials Journal 2012; 31(5): 779 787.

37. Souza LC, Apolonio FM, Souza LP, Carrilho MRO and Saboia VPA. Stability of the Adhesive Interface after Different Artificial Aging Techniques. Journal of Dental Applications - Volume 2 Issue 2 - 2015.

38. De Munck J, Van Landuyt K, Peumans M, Poiteven A, Lambrechts P, Braem M, Van Meerbeek B. A critical review of the durability of adhesion to tooth tissue: methods and results. J Dent Res. 2005; 84: 118-32.

39. Vidal CM, Aguiar TR, Phansalkar R, McAlpine JB, Napolitano JG, Chen SN, Araújo LS, Pauli GF, Bedran-Russo A. Galloyl moieties enhance the dentin biomodification potential of plant-derived catechins. Acta Biomater. 2014; 10:3288-94.

40. De Munck J, Mine A, Poitevin A, Van Ende A, Cardoso MV, Van Landuyt KL. Meta-analytical review of parameters involved in dentin bonding. J Dent Res. 2012; 91:351-7.

41. Kirsten L. Van Landuyt, Johan Snawwaert, Jan De Munck, Marleen Peumans, Yasuhiro Yoshida, Andre Poitevin, Eduardo Coutinho, Kazuomi Suzuki, Paul Lambrechts, Bart Van Meerbeek. Systematic review of the chemical composition of contemporary dental adhesives. Biomaterials 28 (2007)3757-3785.

42. T. K. Vaidyanathan and Jayalakshmi Vaidyanathan. Recent Advances in the Theory and Mechanism of Adhesive Resin Bonding to Dentin: A Critical Review. Journal of Biomedical Materials Research 88B: 558-578, 2009.

43. N. Lehmann, R. Debret1, A. Roméas, H. Magloire, M. Degrange, F. Bleicher, P. Sommer, and D. Seux. Selfetching Increases Matrix Metalloproteinase Expression in the Dentin-Pulp Complex. J Dent Res 88(1):77-82, January, 2009. 
44. Noriko Hiraishi, Ryohei Sono, Islam Sofiqul, Cynthia Yiu, Hiroyuki Nakamura, Masayuki Otsuki, Tsutomu Takatsuka and Junji Tagami. In vitro evaluation of plant-derived agents to preserve dentin collagen. Dental Materials Journal 29(2013) 1048-1054.

45. Annalisa Mazzoni, David H. Pashley, Yoshihiro Nishitani, Lorenzo Breschi, Ferdinando Mannello, Leo Tjaderhane, Manuel Toledano, Edna L. Pashley and Franklin R. Tay. Reactivation of inactivated endogenous proteolytic activities in phosphoric acid-etched dentine by etch-andrinse adhesives. Biomaterials 27 (2006) 4470-4476.

46. Xin Xu,Xue D. Zhou and Christine D. Wu. The Tea Catechin Epigallocatechin Gallate Suppresses Cariogenic Virulence Factors of Streptococcus mutans. Antimicrobial Agents And Chemotherapy, March 2011, p. 1229-1236.

47. Leme-Kraus AA, Aydin B, Vidal CM, Phansalkar RM, Nam JW, McAlpine J, Pauli GF, Chen S, Bedran-Russo AK. Biostability of the Proanthocyanidins-Dentin Complex and Adhesion Studies. J Dent Res. 2017 Apr; 96(4): 406-412.

48. Zheng P, Zaruba M,Attin T, Wiegand A. Effect of different matrix metalloproteinase inhibitors on microtensile bond strength of an etch-and-rinse and a self-etching adhesive to dentin. Oper Dent. 2015;40:80-86.
49. Monteiro TM, Basting RT, Turssi CP, França FM, Amaral FL. Influence of natural and synthetic metalloproteinase inhibitors on bonding durability of an etch-and-rinse adhesive to dentin. Int J Adhes. 2013; 47:83-88.

50. Santiago SL, Osorio R, Neri JR, Carvalho RM, Toledano M. Effect of the flavonoid epigallocatechin-3-gallate on resin-dentin bond strength. J Adhes Dent. 2013; 15: 535-540.

51. Bedran-Russo AK, Pauli GF, Chen SN, Mc Alpine J, Castellan CS, Phansalkar RS. Dentin biomodification: strategies, renewable resources and clinical applications. Dent Mater. 2014; 30:62-76.

52. Han B, Jaurequi J, Tang BW, Nimni ME. Proanthocyanidin: a natural crosslinking reagent for stabilizing collagen matrices. Journal of Biomedical Materials Research A 2003; 65:118-24.

53. Soares CJ, Santos Filho PC, Barreto BC, Mota AS. Effect of previous desensitizer and rewetting agent application on shear bond strength of bonding systems to dentin. Ciencodontol bras. 2006; 9(4):6-11.

54. Sadek FT, Pashley DH, Nishitani Y, Carrilho MR, Donnelly A, Ferrari M, et al. Application of the hydrophobic resin adhesive to acid etched dentine with an alternative wet bonding technique. J Biomed Mater Res .2008; 84:19-29. 